\title{
Las inversiones en conservación no reflejan el valor del patrimonio cultural en la selección de destinos turísticos como Portugal
}

\author{
Mário Brito | gestor de patrimonio, Portugal \\ URL de la contribución <www.iaph.es/revistaph/index.php/revistaph/article/view/3421>
}

El patrimonio cultural es uno de los elementos conformadores de la identidad social y cultural de un pueblo y constituye, cada vez más, un activo esencial para los países en el desarrollo de su actividad turística, con un valor económico unánimemente reconocido.

El vasto patrimonio de países como Portugal y España exige continuas inversiones en su rehabilitación, conservación y puesta en valor, que son llevadas a cabo tanto por agentes privados como por los propios estados. No existen, excepto en áreas restringidas, estudios que cuantifiquen el valor de las inversiones necesarias para la rehabilitación del patrimonio, una tarea que abarca edificios protegidos, centros históricos de ciudades, extensas áreas rurales...; en definitiva, y sólo en lo concerniente al patrimonio construido, una gran variedad de tipologías, seguramente difíciles de cuantificar.

Las inversiones en el patrimonio cultural no se traducen en resultados inmediatos desde el punto de vista económico, ni tampoco se ajustan a los ciclos electorales de 4 años. Este hecho obliga a la existencia de políticas de inversión a largo plazo, lo que no se verifica analizando, por ejemplo, la evolución del porcentaje del PIB invertido en cultura.

La inversión en el patrimonio en un contexto de recesión requiere:

- La inversión en actividades con importante incorporación de mano de obra y materias primas nacionales.

- La creación de condiciones para potenciar el turismo y la atracción de ingresos procedentes del extranjero.

- Evitar el deterioro del patrimonio, que se traduciría en mayores inversiones en el futuro.

- Ofrecer oportunidades de actividad y empleo para mano de obra cualificada.
- Propiciar la actividad de colectivos sociales sensibles a la preservación del patrimonio y del medio ambiente con sus inherentes impactos sociales y económicos.

\section{Impactos de los ingresos por turismo}

Los beneficios del turismo generan un impacto económico en los diversos agentes y empresas y, a través de tasas e impuestos, en el propio Estado.

En las instalaciones hoteleras, la restauración y el comercio con una relación inmediata con el patrimonio cultural -uso de edificios históricos- hay naturalmente un impacto directo entre las inversiones en la rehabilitación y conservación del patrimonio y los ingresos por turismo.

Sin embargo, los ingresos del turismo tienen un impacto muy diversificado sobre la actividad económica y se supone que el Estado, a partir de la recaudación tributaria, invierte en la conservación del patrimonio. En cambio, parece claro que el patrimonio cultural constituye una de las principales motivaciones de los turistas, exceptuando nichos muy específicos como el turismo de negocios. Las inversiones en conservación del patrimonio no reflejan sin duda el valor del patrimonio cultural en la selección de destinos como Portugal.

\section{Modelos de análisis de impacto económico}

Las actividades económicas asociadas al patrimonio cultural se desarrollan, sobre todo, en los campos de la conservación y rehabilitación del patrimonio (mueble e inmueble), del turismo, del merchandinsing, de la actividad editorial, de la producción de contenidos para distintos soportes, de la educación, de los equipamientos culturales y su programación, entre otros.

Naturalmente que el conocimiento del patrimonio, resultado de la investigación científica, constituye un elemento 
a debate ¿el patrimonio cultural en crisis? ¿y ahora qué? | coordina Gabriel Morate Martín

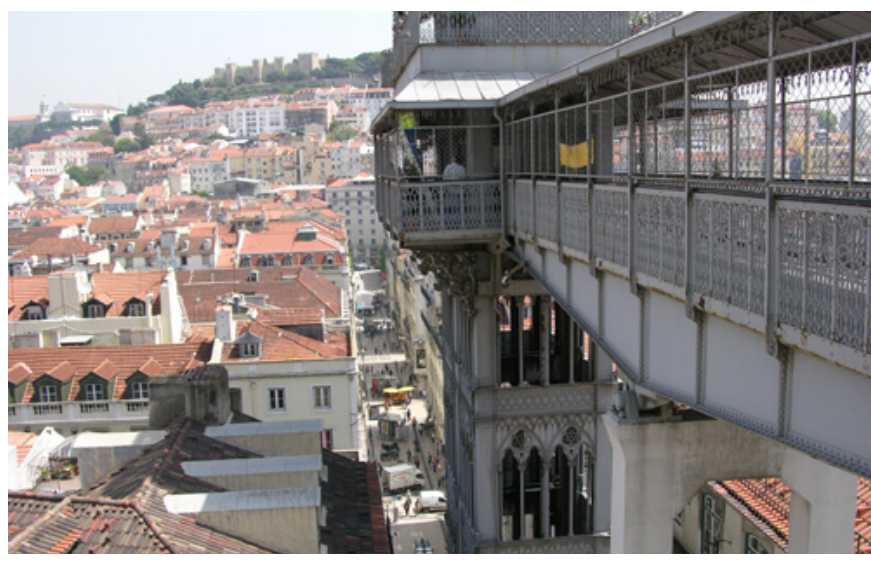

Vista de Lisboa desde el elevador de Santa Justa. Al fondo, castillo de San Jorge | foto Víctor Fernández Salinas

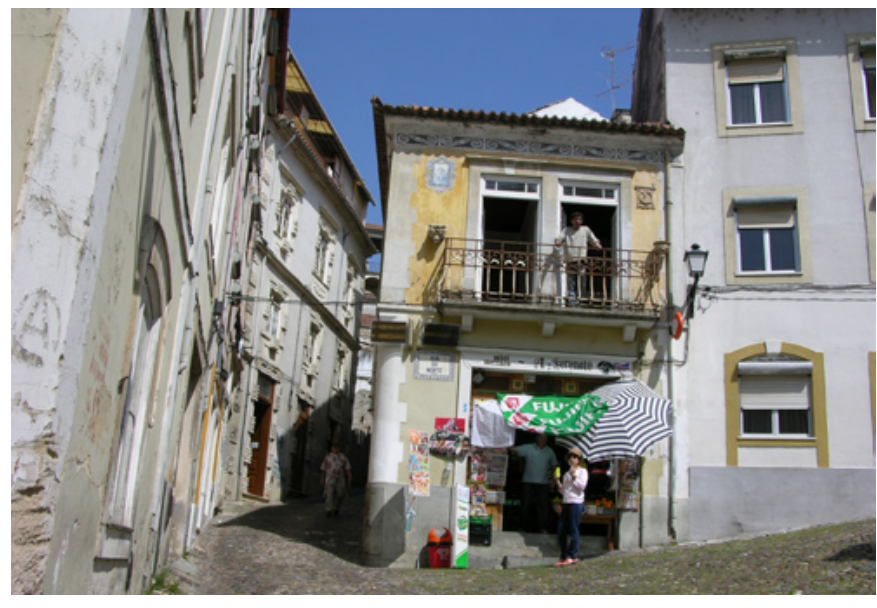

Calles de Coimbra | foto Víctor Fernández Salinas

estructurante de todas estas actividades. No tenemos todavía en Portugal estudios para establecer modelos de análisis del impacto económico de la inversión en investigación en patrimonio cultural. Sin embargo, la percepción es que no puede plantearse un trabajo riguroso en el ámbito de cualquier vertiente de la actividad patrimonial si de hecho no existe un serio y riguroso conocimiento del patrimonio.

\section{Apertura de los equipamientos culturales}

La relación entre administraciones públicas-sector privado es un tema complejo que depende de opciones políticas y, sobre todo, del papel que se pretenda que desempeñe el Estado, de mero regulador o de interviniente activo en la sociedad y en la economía.

En cualquiera de los casos me parece que hay algunos principios que deben ser tenidos en consideración en esta ecuación:

- El impacto del patrimonio cultural en la sociedad se verifica en aspectos sociales y culturales que no pueden ser descuidados.

- El impacto económico del patrimonio cultural ofrece resultados directos, indirectos e inducidos. Si los primeros pueden ser de alguna forma cuantificados a pesar de la falibilidad de los modelos que apliquemos, el tercero, en gran medida de naturaleza cualitativa, es de muy difícil o imposible cuantificación.

- La mayoría de los equipamientos culturales tendrán que depender siempre de la inversión pública, en forma de subvenciones directas o mediante el uso de los fondos comunitarios, que también son recursos públicos.

- Es exigible una mayor apertura de los equipamientos culturales a alianzas con el sector privado, porque redundaría en la incorporación de mayor masa crítica y dinamismo, que son esenciales.

- Equipamientos culturales como los museos, bibliotecas, archivos, centros culturales y organismos de la administración cultural, constituyen una extraordinaria red repartida por todo el territorio que aún no ha sido adecuadamente incorporada y estructurada como red de cultura y promoción de la actividad económica. 